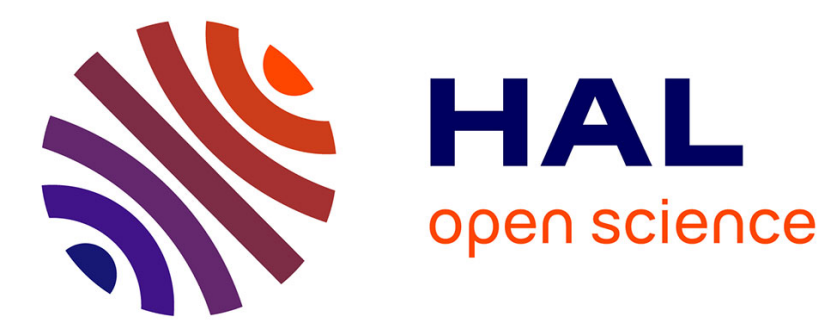

\title{
Putative involvement of Thioredoxin $h$ in early response to gravitropic stimulation of poplar stems
}

Wassim Azri, Nicole Brunel, Jérôme Franchel, Ichrak Ben Rejeb, Jean-Pierre

Jacquot, Jean-Louis J.-L. Julien, Stéphane Herbette, Patricia Roeckel-Drevet

\section{- To cite this version:}

Wassim Azri, Nicole Brunel, Jérôme Franchel, Ichrak Ben Rejeb, Jean-Pierre Jacquot, et al.. Putative involvement of Thioredoxin $\mathrm{h}$ in early response to gravitropic stimulation of poplar stems. Journal of Plant Physiology, 2013, 170 (7), pp.707-711. 10.1016/j.jplph.2012.12.017 . hal-01190298

\section{HAL Id: hal-01190298 \\ https://hal.science/hal-01190298}

Submitted on 29 May 2020

HAL is a multi-disciplinary open access archive for the deposit and dissemination of scientific research documents, whether they are published or not. The documents may come from teaching and research institutions in France or abroad, or from public or private research centers.
L'archive ouverte pluridisciplinaire HAL, est destinée au dépôt et à la diffusion de documents scientifiques de niveau recherche, publiés ou non, émanant des établissements d'enseignement et de recherche français ou étrangers, des laboratoires publics ou privés. 


\title{
Putative involvement of Thioredoxin $h$ in early response to gravitropic stimulation of poplar stems
}

\author{
Wassim Azri ${ }^{\mathrm{a}, *}$, Nicole Brunel ${ }^{\mathrm{b}, \mathrm{c}}$, Jérôme Franchel ${ }^{\mathrm{b}, \mathrm{c}}$, Ichrak Ben Rejeb ${ }^{\mathrm{a}}$, Jean-Pierre Jacquot ${ }^{\mathrm{d}}$, \\ Jean-Louis Julien ${ }^{\mathrm{b}, \mathrm{c}}$, Stéphane Herbette ${ }^{\mathrm{b}, \mathrm{c}}$, Patricia Roeckel-Drevet ${ }^{\mathrm{b}, \mathrm{c}}$ \\ a Laboratoire de Biologie et Physiologie Végétales, Département de Biologie, Faculté des Sciences de Tunis, campus universitaire, 1060, Tunis, Tunisia \\ b Clermont Université, Université Blaise Pascal, UMR547 PIAF, BP 10448, F-63000 Clermont-Ferrand, France \\ ${ }^{\mathrm{c}}$ INRA, UMR547 PIAF, F-63100 Clermont-Ferrand, France

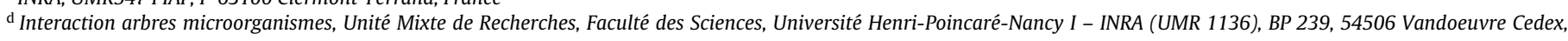 \\ France
}

\section{A R T I C L E I N F O}

\section{Article history:}

Received 8 September 2012

Received in revised form

12 December 2012

Accepted 14 December 2012

Available online 5 March 2013

\section{Keywords:}

Amyloplast

Thioredoxin

Gravitropism

Poplar

\begin{abstract}
A B S T R A C T
Gravity perception and gravitropic response are essential for plant development. In herbaceous species, it is widely accepted that one of the primary events in gravity perception involves the displacement of amyloplasts within specialized cells. However, the early signaling events leading to stem reorientation are not fully known, especially in woody species in which primary and secondary growth occur. Thirty-six percent of the identified proteins that were differentially expressed after gravistimulation were established as potential Thioredoxin targets. In addition, Thioredoxin $h$ expression was induced following gravistimulation. In situ immunolocalization indicated that Thioredoxin $h$ protein co-localized with the amyloplasts located in the endodermal cells. These investigations suggest the involvement of Thioredoxin $h$ in the first events of signal transduction in inclined poplar stems, leading to reaction wood formation.
\end{abstract} (c) 2013 Elsevier GmbH. All rights reserved.

\section{Introduction}

It is widely accepted that one of the primary events in gravity sensing in vascular plants involves the displacement or settling of dense starch-containing amyloplasts, which can occur in seconds to minutes depending on the plant tissue (Blancaflor and Masson, 2003). Studies with herbaceous plants (Kiss et al., 1997; Fukaki et al., 1998) provide evidence that perception of gravity in younger stems is mediated by sedimentable amyloplasts located in the endodermal starch sheath cells along the stem axis. In trees, sedimentable amyloplasts in the endodermal cells may play a role in gravity perception, leading to secondary xylem formation, eccentric growth and reaction wood formation in gravi-stimulated tree stems (Nakamura et al., 2001). How the displacement of amyloplasts might trigger a signaling cascade is still a matter of debate (Perera et al., 2006). Several different second messengers and proteins have been suggested to be involved in signal transduction of gravitropism (Chang et al., 2003; Perera et al., 2006; Azri et al., 2009). Reactive oxygen species (ROS) are possible second messengers, since Joo et al. (2001) have reported that production of ROS is essential for auxin-induced gravitropic signaling in maize

\footnotetext{
* Corresponding author. Tel.: +33 21697243698.

E-mail addresses: azwassim@yahoo.fr, azwassim@voila.fr (W. Azri).
}

roots. Redox-dependent regulators are central and flexible mechanisms to control metabolic and developmental activities of the cells. Thioredoxins (Trxs) are $12 \mathrm{kDa}$ proteins that contribute to the redox control by dithiol/disulfide exchange. In plants, a large number of genes encode Trxs, and 19 different isoforms have been identified in Arabidopsis thaliana and were grouped in six subfamilies: the Trxs $f, h, m, o, x$ and $y$ (Buchanan and Luan, 2005). Recently, plastidial thioredoxins from the z-type have been described (Chibani et al., 2011). Trxs $f, m, x$ and $y$ are localized in chloroplasts, whereas Trxs $o$ are found in mitochondria. Trx $m$ was detected in amyloplasts from wheat starchy endosperm (Balmer et al., 2006). Thioredoxins $h$ were first found in the cytoplasm compartment, then some isoforms were purified from mitochondria and endoplasmic reticulum, and nuclear localization has also been reported (Buchanan and Balmer, 2005). Trxs $h$ are encoded by a multigenic family of 8 genes in $A$. thaliana, and at least five in Populus sp. (Gelhaye et al., 2004). Trxs $h$ are involved in multiple processes, such as reserve breakdown that sustains early seedling growth of germinating cereal seeds (Wong et al., 2002), or self-incompatibility (Cabrillac et al., 2001), in carbon and nitrogen metabolism (Wong et al., 2003). They are also implicated in the cellular protection against oxidative stress, in particular during seed desiccation and germination (Serrato and Cejudo, 2003). Furthermore, Trxs $h$ are electron donors to several enzymes involved in the protection against oxidative stress such as 
Table 1

Putative or established Thioredoxin targets among differentially expressed proteins expressed in poplar stems after gravi-stimulation.

\begin{tabular}{|c|c|c|c|}
\hline \multicolumn{4}{|l|}{ Putative or established Thioredoxin targets } \\
\hline $40 \mathrm{~S}$ ribosomal protein $\mathrm{S} 12$ & 2 & GSH-dependent dehydroascorbate reductase 1 (EC 1.8.5.1) & 1 \\
\hline Actin 3 & 1 & HSP90 co-chaperone p23 & 2 \\
\hline Adenosine kinase & 2 & Malate dehydrogenase, NAD-dependent (EC 1.1.1.37) & 1 \\
\hline ATP synthase, beta subunit (EC 3.6.3.14) & 1 & Molecular chaperones HSP70 superfamily & 1 \\
\hline Tubulin alpha- 5 chain & 1 & Nucleoside-diphosphate kinase 1 (EC 2.7.4.6) & 1 \\
\hline Beta tubulin & 1 & Oxygen Evolving Enhancer 1 & 1 \\
\hline Calreticulin 1 & 2 & Oxygen Evolving Enhancer 2 & 2 \\
\hline Chaperonin, Cpn60/Hsp60p (3.6.4.9) & 1 & Pyruvate dehydrogenase E1 Beta subunit isoforme 1 (EC 1.2.4.1) & 1 \\
\hline Chlorophyll A/B binding protein precursor & 2 & RuBisCO large subunit (EC 4.1.1.39) & 1 \\
\hline CuZn-superoxide dismutase (EC 1.15.1.1) & 1 & S-adenosylmethionine synthetase (EC 2.5.1.6) & 1 \\
\hline Elongation factor 1 -alpha & 1 & Translationally controlled tumor protein & 1 \\
\hline Gluthatione s-transferase (EC 2.5.1.18) & 1 & Triosephosphate isomerase (EC 5.3.1.1) & 1 \\
\hline
\end{tabular}

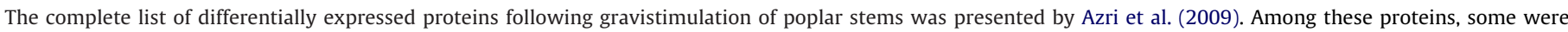
putative or established Thioredoxin targets according to Buchanan and Balmer (2005) [1] and/or Montrichard et al. (2009) [2].

peroxiredoxin, methionine sulfoxide reductase, and glutathione reductase (Rouhier et al., 2001; Gelhaye et al., 2003; Jung et al., 2002). In addition to their role as antioxidant, Trxs $h$ was proposed to be involved in modulating redox-dependent signaling cascades (Dietz, 2003).

Starting from the observation that many proteins involved in gravitropic response are potential Thioredoxins targets, we investigated the expression and localization of thioredoxin $h$ in the early response to gravitropic stimulation in poplar stems.

\section{Materials and methods}

\section{Plant material and culture conditions}

Hybrid poplar (Populus tremula $x$ Populus alba), clone INRA n ${ }^{\circ}$. 717-1-B4 was multiplied clonally in vitro on Murashige and Skoog medium (Murashige and Skoog, 1962), acclimatized in hydropony (Herbette et al., 2004), and grown in a controlled environment growth chamber $\left(16 \mathrm{~h}\right.$ photoperiod at $60 \mu \mathrm{mol} \mathrm{m}^{-2} \mathrm{~s}^{-1}, 22^{\circ} \mathrm{C} / 18^{\circ} \mathrm{C}$ (day/night) and $70 \%$ of relative humidity). At the 14 internodes stage, the poplars showing straight stems were transferred on a new device for tilting (Azri et al., 2009).

After one week on the device in a straight position, poplars showing 20 developed internodes were inclined at $35^{\circ}$ from the vertical axis for $0,10,20,30,45 \mathrm{~min}, 1 \mathrm{~h}, 3 \mathrm{~h}$, and $6 \mathrm{~h}$ as described earlier by Azri et al. (2009). Starting from the base, internodes 1-5 (showing preponderant secondary growth) were harvested from inclined and non-inclined plants, frozen in liquid nitrogen and stored at $-80^{\circ} \mathrm{C}$ until RNA extraction.

\section{RNA extraction and real-time RT-PCR experiments}

For each time of the kinetics, the basal portions of two stems were used. Total RNA was extracted according to the method of Chang et al. (1993) and then treated with RNAsefree RQ1 DNase (Promega, Charbonnières-les-Bains, France). RNA concentration and quality were determined at 260 and $280 \mathrm{~nm}$ using the NanoDrop $1000^{\mathrm{TM}}$ spectrophotometer (Thermo Fisher Scientific, Wilmington, U.S.A.) and checked by agarose gel electrophoresis.

The real-time RT-PCR amplifications were performed according to Mai et al. (2009). Trx $h$ transcripts were detected by amplifying $178 \mathrm{bp}$ with primers TrxF 5'-AGGGAAAAGGGTCTCAGAAA$3^{\prime}$ and TrxR 5'-ATTGCCTCCACATTCCACTC-3'. These primers detected transcripts corresponding to the $\operatorname{Trx} h$ protein that was upregulated in basal internodes of Populus tremula $\mathrm{X}$ alba after 1 week inclination (Azri et al., 2009) and similar to POPTR_0005s25420.1 (Phytozome http://www.phytozome.
Net - JGI v2.2). The reference genes 18S RNA and Ubiquitin transcripts (POPTR_0012s01250, Phytozome) were amplified using the primers 18 SF 5'-CTTCGGGATCGGAGTAATGA-3', 18SR 5'GCGGAGTCCTAGAAGCAACA-3', and UbiF 5'-CCCGGCTCTAACCATA TCCA-3', UbiR 5'-GGGTCCAGCTTCTTGCAGTC-3', respectively. The reference genes were combined into an index using the BestKeeper software tool (http://www.wzw.tum.de/gene-quantifaccation/ bestkeeper.html) (Pfaffl et al., 2004). Target gene abundance was conventionally normalized using this BestKeeper Index (I) using the delta-delta method mathematical model (McMaugh and Lyon, 2003).

\section{Histochemical and immunolocalization analyses}

After 45 min inclination, basal stem portions were prepared for histochemical analysis as described previously (Azri et al., 2009). Briefly, stems portions were fixed in a solution containing 3.7\% $(\mathrm{v} / \mathrm{v})$ formaldehyde, $5 \%(\mathrm{v} / \mathrm{v})$ acetic acid, $50 \%(\mathrm{v} / \mathrm{v})$ ethanol, for $4 \mathrm{~h}$ at $4{ }^{\circ} \mathrm{C}$. The samples were then dehydrated and embedded in L.R.White resin (Sigma-Aldrich). Semi-thin sections were performed and the Periodic acid/Schiff(PAS) reaction was used to detect starch and polysaccharides (Jensen, 1962). Stained sections were dried, mounted in Eukitt (Kindler GmbH \& Co, Freiburg, Germany) and examined under a Zeiss Axioplan 2 microscope. Data were recorded

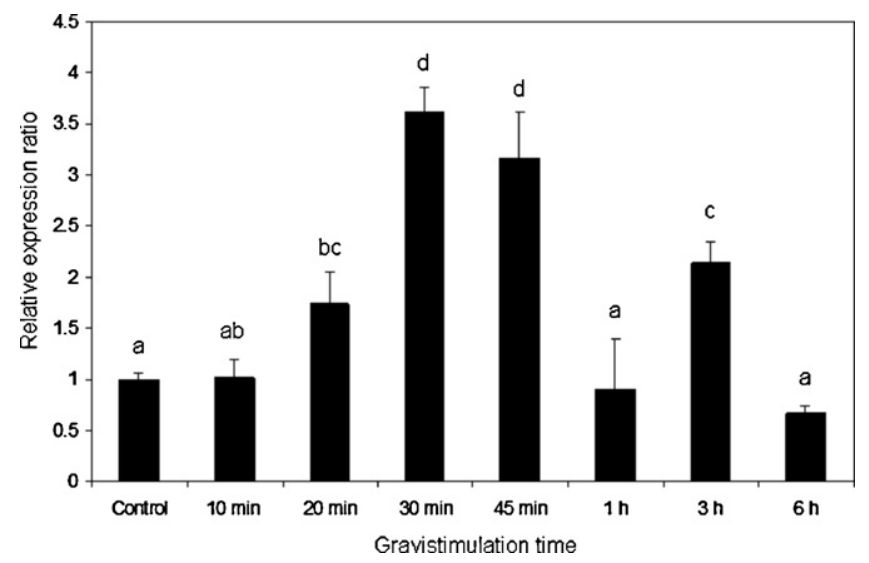

Fig. 1. Time course accumulation of $\operatorname{Trx} h$ after gravitational stimulus. Total RNAs were extracted from basal internodes of inclined plants for 0 (control), 10, 20, 30, $45 \mathrm{~min}, 1 \mathrm{~h}, 3 \mathrm{~h}$ and $6 \mathrm{~h}$. The accumulation of relative transcripts was determined by RT-qPCR. Mean values (+SE) of three technical replicates are shown. For each time of the kinetics, one plant is analyzed. Similar results were obtained on a second series of plants (data not shown). Data were analyzed using ANOVA (Stagraphics Plus version 5.1). Different letters indicate significant differences $(P<0.05)$ for Fisher's LSD pairwise comparisons. 
using a digital camera (AxioCam HR, Zeiss) with AxioVision digital imaging software.

Samples embedded in L.R.-White resin for histochemical analysis were also used for in situ immunolocalization as described by Dusotoit-Coucaud et al. (2010). The primary antibody directed against the protein Trx $h 1$ (Rouhier et al., 2001) from Populus tremula X Populus tremuloïdes (similar to POPTR_0005s25420.1) was provided by Dr. Rouhier at the University Henry Poincaré, Nancy, France. The goat anti-rabbit antibody conjugated to alkaline phosphatase (Sigma, Saint-Quentin Fallavier, France) was used as secondary antibody. For the revelation, sections were incubated with chromogenic substrates nitroblue tetrazolium and 5-bromo-4-chloro-3-indolyl phosphate (Bio-Rad, Marnes-laCoquette, France). Color development was stopped by washing in $\mathrm{H}_{2} \mathrm{O}$. Sections were then mounted onto microscope slides, air dried and covered with cover slips for microscopy using Eukitt mounting medium.

\section{Results and discussion}

The data presented here suggest a role of Trxs $h$ in the early response to gravistimulation of poplar stems, in relation with the amyloplast-linked mechanism of gravity sensing.

Earlier expression studies carried out at the proteomic level on proteins from control and inclined poplar stems showed that about $40 \%$ of the proteins analyzed undergo significant changes following gravi-stimulation (Azri et al., 2009). The development of proteomic tools led to the identification of many Trxs $h$ potential targets (Yano et al., 2001; Maeda et al., 2003; Marx et al., 2003; Yamazaki et al., 2004).

Here, we observed that among 60 spots that were successfully identified, 36 spots were potential targets of Trxs, according to the listings established by Buchanan and Balmer (2005) and Montrichard et al. (2009). These 36 spots represented 24 proteins (Table 1 ). Among the 24 proteins listed, 5 are plastidial proteins.

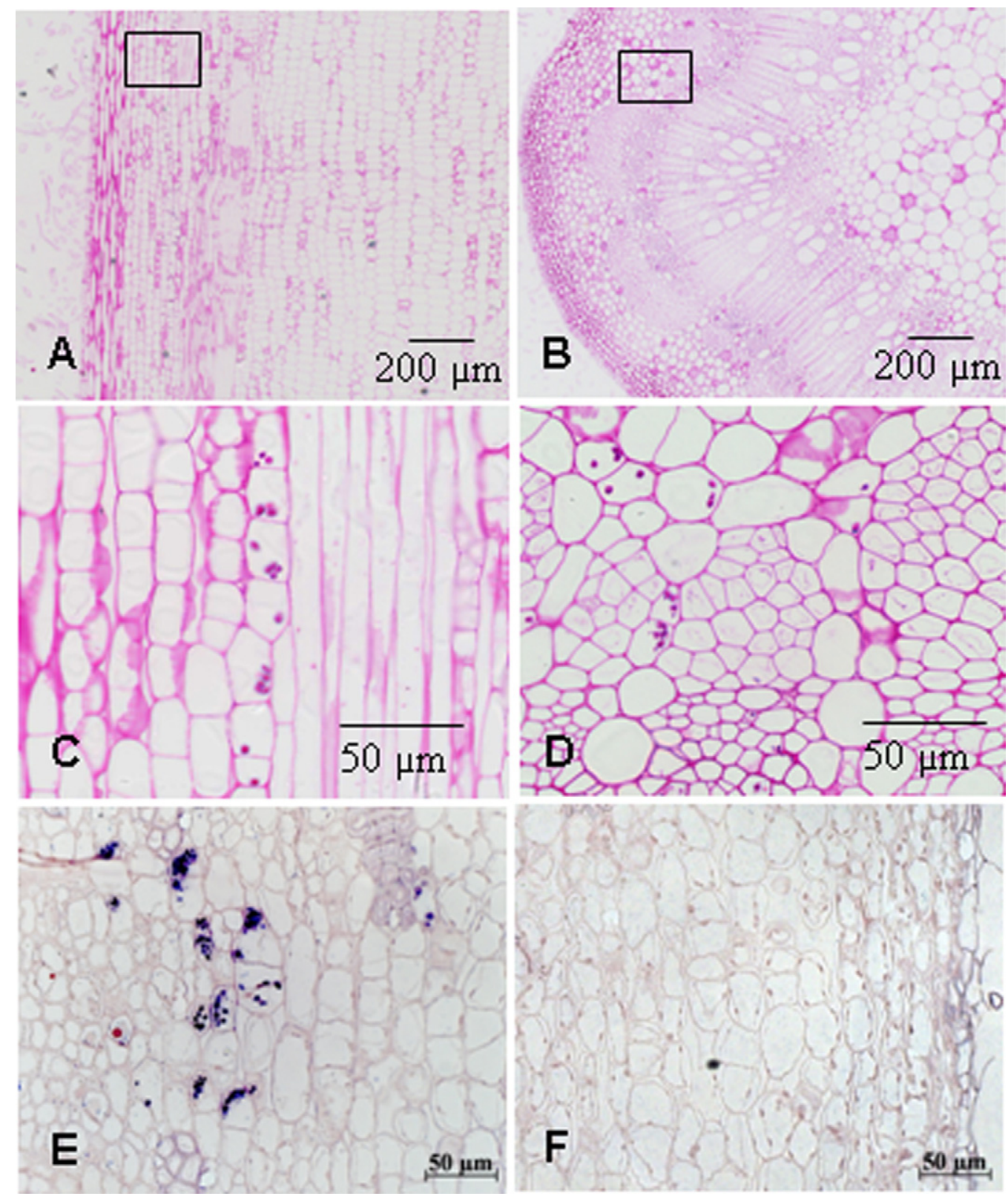

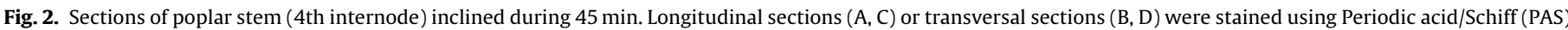

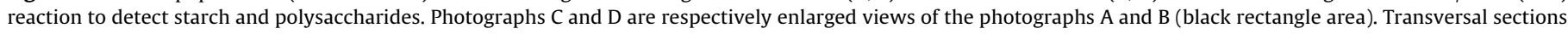
were probed with the antibody anti-Trx $h 1(E)$ or incubated without primary antibody as a negative control (F). 
Previous reports have listed chloroplastic proteins as cytosolic thioredoxin targets. Yamazaki et al. (2004), investigating possible cytosolic thioredoxin targets in A. thaliana cells, found some chloroplast proteins and suggested that they came from plastid contaminants. The observation that most proteins regulated after gravi-stimulation are probable Trxs $h$ targets was also made in Populus euphratica Oliv. upon heat stress (Ferreira et al., 2006). The proteins, potentially regulated both by gravi-stimulation and Thioredoxins, are involved in various processes (Table 1, Azri et al., 2009), among which are cytoskeleton organization and biogenesis (actin-3, Tubulin-alpha-5-chain, Beta-tubulin). The displacement of amyloplasts following gravi-stimulation may modify the cell wall-plasma membrane-cytoskeleton structural continuum and trigger signaling cascades (Perera et al., 2006). We assume that Trx $h$ may have a particular role in signal transduction after amyloplast displacement in the cytosolic compartment.

Trx $h$ expression was induced by gravitropic stimulation. Indeed, the real-time quantitative RT-PCR analysis showed two significant increases of Trx $h$ mRNAs: from 20 to $30-45 \mathrm{~min}$, and $3 \mathrm{~h}$ after gravistimulation, in basal internodes (Fig. 1). An increase in $\operatorname{Trx} h$ mRNA expression levels has also been observed following salt treatment of rice seedlings (Zhang et al., 2011). Such regulation of Trxs suggests that redox balance is affected in the early step of gravistimulation. We previously observed that Thioredoxin $h$ was also expressed one week after stem inclination (Azri et al., 2009). This is in agreement with the finding that production of ROS is essential for auxin-induced gravitropic signaling in maize roots (Joo et al., 2001, 2005).

Using the Periodic acid/Schiff (PAS) reaction to detect starch and polysaccharides, we observed amyloplast sedimentation at the base of starch sheath cells of poplar stems (Fig. 2A and C). In agreement with our observations, Nakamura et al. (2001) found that the upright reorientation of woody stems of Japanese Cherry was correlated with the sedimentation of the amyloplasts at the base of endodermal cells. Using an in situ immunolocalization approach, $\operatorname{Trx} h 1$ co-localized with the amyloplasts of endoderm cells of the stem (Fig. 2E). A control section incubated without primary antibody (Fig. 2F) confirmed the specificity of the signal. The endoderm, which contains the amyloplasts, has been suggested as essential for shoot gravitropism (Fukaki et al., 1998). Since $\operatorname{Trx} h$ are expected in the cytoplasm compartment, the co-localization of $\operatorname{Trx} h 1$ with the amyloplasts might indicate that $\operatorname{Trx} h$ targets are found in the outer membrane of the amyloplats envelope. These targets may be essential for transduction of the gravitropic signal. Isolation and characterization of proteins from this outer envelope that interact with Trx $h$ could aid in understanding the signaling cascade following amyloplast displacement. We cannot exclude the possibility that the antibody anti-Trx $h 1$ detected the presence of $\operatorname{Trx} h$ inside the amyloplasts. To date, only Trx $m$ has been detected in isolated amyloplasts from wheat endosperm (Balmer et al., 2006). Thus, Trxs could act as regulatory links between the redox signal generated by gravitropic stimulation (Joo et al., 2001) and metabolic processes in amyloplasts. For example, Kolbe et al. (2005) have shown that cytoplasmic trehalose metabolism and sugar utilization in amyloplasts are linked via Thioredoxin-mediated redox transfer.

In conclusion, our results support the involvement of Thioredoxin $h$ in the early response to gravitropic stimulus leading to reaction wood formation and poplar stem reorientation. Further studies need to be done to discriminate among the Thioredoxin $h$ isoforms involved. Indeed, $\operatorname{Trxs} h$ form a large and diverse group of protein disulfide reductases, but the function of each isoform is still unclear (Gelhaye et al., 2004). The next step would be to identify the components interacting with amyloplast associatedThioredoxin in order to dissect the events linked to gravity sensing.

\section{Acknowledgments}

We thank Nicolas Rouhier (Université Henri Poincaré - Nancy I, France) for kindly providing the $\operatorname{Trx} h 1$ antibodies, Sylvaine Labernia for her help in molecular technical work and Christelle Boisselet for producing the poplar plants.

\section{References}

Azri W, Chambon C, Herbette S, Brunel N, Coutand C, Leplé J-C, et al. Proteome analysis of apical and basal regions of poplar stems under gravitropic stimulation. Physiologia Plantarum 2009;136:193-8.

Balmer Y, Vensel WH, Cai N, Manieri W, Schürmann P, Hurkman WJ, et al. A complete ferredoxin/thioredoxin system regulates fundamental processes in amyloplasts. Proc Natl Acad Sci USA 2006;103:2988-93.

Blancaflor EB, Masson PH. Plant gravitropism. Unraveling the ups and downs of a complex process. Plant Physiol 2003;133:1667-90.

Buchanan BB, Balmer Y. Redox regulation: a broadening horizon. Ann Rev Plant Biol 2005;56:187-220.

Buchanan BB, Luan S. Redox regulation in the chloroplast thylakoid lumen: a new frontier in photosynthesis research. J exp Bot 2005;56:1439-47.

Cabrillac D, Cock JM, Dumas C, Gaude T. The S-locus receptor kinase is inhibited by thioredoxins and activated by pollen coat proteins. Nature 2001;410:220-3.

Chang S, Puryear J, Cairney J. A simple and efficient method for isolating RNA from pine trees. Plant Mol Biol Rep 1993;11(2):113-6.

Chang SC, Cho MH, Kim S-K, Lee JS, Kirakosyan A, Kaufman PB. Changes in phosphorylation of 50 and $53 \mathrm{kDa}$ soluble proteins in graviresponding oat (Avena Sativa) shoots. J Exp Bot 2003;384:1013-22.

Chibani K, Tarrago L, Scuhrmann P, Jacquot JP, Rouhier N. Biochemical properties of poplar thioredoxin z. FEBS Lett 2011:1077-81.

Dietz KJ. Plant peroxiredoxins. Annu Rev Plant Biol 2003;54:93-7.

Dusotoit-Coucaud A, Kongsawadworakul P, Maurousset L, Viboonjun U, Brunel N, Pujade-Renaud V, et al. Ethylene stimulation of latex yield depends on the expression of a sucrose transporter (HbSUT1B) in rubber tree (Hevea brasiliensis). Tree Physiol 2010;30:1586-98.

Ferreira S, Hjerno K, Larsen M, Wingsle G, Larsen P, Fey S, et al. Proteome profiling of Popolus euphratica Oliv. upon heat stress. Ann Bot 2006;98:361-77.

Fukaki HJ, Wysocka-Diller J, Kato T, Fujisawa H, Benty PN, Tasaka M. Genetic evidence that the endodermis is essential for shoot gravitropism in Arabidopsis thaliana. Plant J 1998;14:425-30.

Gelhaye E, Rouhier N, Jacquot JP. Evidence for a subgroup of thioredoxin h that requires GSH/Grx for its reduction. FEBS Lett 2003;555:443-8.

Gelhaye E, Rouhier N, Jacquot J-P. The thioredoxin h system of higher plants. Plant Physiol Biochem 2004;42:265-71.

Herbette S, Brunel N, Prensier G, Julien JL, Drevet JR, Roeckel-Drevet P. Immunolocalization of a plant glutathione peroxidase-like protein. Planta 2004;219:784-9.

Jensen WA. Botanical histochemistry. San Francisco: W. H. Freeman and Co; 1962.

Joo JH, Bae YS, Lee JS. Role of auxin-induced reactive oxygen species in root gravitropism. Plant Physiol 2001;126:1055-60.

Joo JH, Yoo HJ, Hwang I, Lee JS, Nam KH, Bae YS. Auxin-induced reactive oxygen species production requires the activation of phosphatidylinositol 3-kinase. FEBS Lett 2005:579:1243-8.

Jung BG, Lee KO, Lee SS, Chi YH, Jang HH, Kang SS, et al. A Chinese cabbage cDNA with high sequence identity to phospholipids hydroperoxide glutathione peroxidase encodes a novel isoform of thioredoxin-dependent peroxidise. J Biol Chem 2002;277:12572-8

Kiss JZ, Guisinger MM, Miller AJ, Stackhouse KS. Reduced gravitropism in hypocotyls of starch-deficient mutants of Arabidopsis. Plant Cell Physiol 1997;38:518-25.

Kolbe A, Tiessen A, Schluepmann H, Paul M, Ulrich S, Geigenberger P. Trehalose 6phosphate regulates starch synthesis via posttranslational redox activation of ADP-glucose pyrophosphorylase. Proc Natl Acad Sci USA 2005;102:11118-23.

Maeda M, Finnie C, Svensson B. Cy5 maleimide-labelling for sensitive detection of free thiols in native protein extracts: identification of seed proteins targeted by barley Thioredoxin h isoforms. Biochem J 2003;24:497-507.

Mai J, Herbette S, Vandame M, Kositsup BA, Kasemsap P, Cavaloc E, et al. Effect of chilling on photosynthesis and antioxidant enzymes in Hevea brasiliensis Muell. Arg Trees: Struct Funct 2009;23:863-74.

Marx C, Wong JH, Buchanan BB. Thioredoxin and germinating barley: targets and protein redox changes. Planta 2003;216:454-60.

McMaugh SJ, Lyon BR. Real-time quantitative RT-PCR assay of gene expression in plant roots during fungal pathogenesis. Biotechniques 2003;34:982-6.

Montrichard F, Alkhalfioui F, Yano H, Vensel WH, Hurkman WJ, Buchanan BB. Thioredoxin targets in plants: the first 30 years. J Proteomics 2009;72:542-74.

Murashige T, Skoog F. A revised medium for rapid growth and bioassay with tobacco tissue culture. Physiol Plant 1962;15:473-92.

Nakamura T, Negishi Y, Funada R, Yamada M. Sedimentable amyloplasts in starch sheath cells of woody stems of Japanese Cherry. Adv Space Res 2001;27:957-60.

Perera IY, Hung CY, Brady S, Muday GK, Boss WF. A universal role for inositol $1,4,5$ trisphosphate-mediated signaling in plant gravitropism. Plant Physio 2006;140:746-60.

Pfaffl MW, Tichopad A, Prgomet C, Neuvians T. Determination of stable housekeeping genes, differently regulated target genes and sample integrity BestKeeper-Excelbased tool using pair-wise correlations. Biotechnol Lett 2004;26:509-15. 
Rouhier N, Gelhaye E, Sautiere PE, Brun A, Laurent P, Tagu D, et al. Isolation and characterization of a new peroxiredoxin from poplar sieve tubes that uses either glutaredoxin or thioredoxin as a proton donor. Plant Physiol 2001;127: 1299-309.

Serrato AJ, Cejudo FJ. Type-h thioredoxins accumulate in the nucleus of developing wheat seed tissues suffering oxidative stress. Planta 2003;217:392-9.

Wong JH, Kim YB, Ren PH, Cai N, Cho MJ, Hedden P, et al. Transgenic barley grain overexpressing thioredoxin shows evidence that the starchy endosperm communicates with the embryo and the aleurone. Proc Natl Acad Sci USA 2002;99:16325-30.
Wong JH, Balmer Y, Cai N, Tanaka CK, Vensel WH, Hurkman WJ, et al. Unraveling thioredoxin-linked metabolic processes of cereal starchy endosperm using proteomics. FEBS Lett 2003;547:151-6.

Yamazaki D, Motohashi K, Kasama T, Hara Y, Hisabori T. Target proteins of the cytosolic thioredoxins in Arabidopsis thaliana. Plant Cell Physiol 2004;45:18-27. Yano H, Wong JH, Lee YM, Cho MJ, Buchanan BB. A strategy for the identification of proteins targeted by thioredoxin. Proc Natl Acad Sci USA 2001;98:4794-9.

Zhang CJ, Zhao BC, Ge WN, Zhang YF, Song Y, Sun DY, et al. An apoplastic H-type thioredoxin is involved in the stress response through regulation of the apoplastic reactive oxygen species in rice. Plant Physiol 2011;157:1884-99. 